\title{
BMJ Open Modelling the cost of community interventions to reduce child mortality in South Africa using the Lives Saved Tool (LiST)
}

Lungiswa, LL Nkonki, ${ }^{1}$ Lumbwe, L Chola, ${ }^{2}$ Aviva, A Tugendhaft, ${ }^{3}$ Karen, $\mathrm{K} \mathrm{Hofman}^{3}$

To cite: Nkonki L,LL, Chola L,L, Tugendhaft A,A, et al. Modelling the cost of community interventions to reduce child mortality in South Africa using the Lives Saved Tool (LiST). BMJ Open 2017;7:e011425. doi:10.1136/ bmjopen-2016-011425

- Prepublication history and additional material for this paper are available online. To view these files please visit the journal online (http://dx.doi. org/10.1136/bmjopen-2016011425).

Received 14 June 2016 Revised 18 January 2017 Accepted 17 March 2017

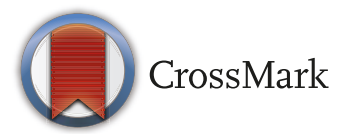

${ }^{1}$ Division of Community Health Centre for Health Systems and Services Research, Faculty of Medicine and Health Sciences, Stellenbosch University, Tygerberg, South Africa ${ }^{2}$ Population Health, Health Systems and Innovation, Human Science Research Council, Pretoria, South africa ${ }^{3}$ PRICELESS SA-MRC/Wits Rural Public Health and Health Transitions Research Unit (Agincourt), School of Public Health, Faculty of Health Sciences, University of the Witwatersrand, Johannesburg, South africa

Correspondence to Dr Lungiswa, LL Nkonki; Inkonki@sun.ac.za

\section{ABSTRACT}

Objective To estimate the costs and impact on reducing child mortality of scaling up interventions that can be delivered by community health workers at community level from a provider's perspective.

Setting In this study, we used the Lives Saved Tool (LiST), a module in the spectrum software. Within the spectrum software, LiST interacts with other modules, the AIDS Impact Module, Family Planning Module and Demography Projections Module (Dem Proj), to model the impact of more than 60 interventions that affect cause-specific mortality.

Participants DemProj Based on National South African Data.

Interventions A total of nine interventions namely, breastfeeding promotion, complementary feeding, vitamin supplementation, hand washing with soap, hygienic disposal of children's stools, oral rehydration solution, oral antibiotics for the treatment of pneumonia, therapeutic feeding for wasting and treatment for moderate malnutrition.

Primary and secondary outcome measures Reducing child mortality.

Results A total of 9 interventions can prevent 8891 deaths by 2030 . Hand washing with soap (21\%) accounts for the highest number of deaths prevented, followed by therapeutic feeding $(19 \%)$ and oral rehydration therapy (16\%). The top 5 interventions account for $77 \%$ of all deaths prevented. At scale, an estimated cost of US\$169.5 million (US\$3 per capita) per year will be required in community health worker costs.

Conclusion The use of community health workers offers enormous opportunities for saving lives. These programmes require appropriate financial investments. Findings from this study show what can be achieved if concerted effort is channelled towards the identified set of life-saving interventions.

\section{BACKGROUND}

More than 40000 children under the age of 5 years die every year in South Africa from preventable causes, mainly diarrhoea and pneumonia. ${ }^{12}$ Progress has been made in the last decade, with child and infant mortality reducing significantly. Under-5 mortality
Strengths and limitations of this study

- The Lives Saved Tool is a widely used robust priority setting tool that has been extensively reviewed and used to influence policy in low and middle-income countries.

- The model used in this analysis offers an alternative to measured impact of community health interventions, which can be costly undertakings.

- One limitation of this analysis is that interventions for saving the lives of children are included as standalone interventions and not packages of care, thus the overall impact is potentially overestimated.

- While intervention costs are provided, this study is not a full economic evaluation, which only considers costs of labour, drugs and supplies associated with the essential interventions.

reduced from 56 deaths per 1000 live births in 2009 to $39 / 1000$ in 2014 and infant mortality from $39 / 1000$ (2009) to $28 / 1000$ (2014). ${ }^{3}$ This progress has occurred at a time during which there has been rapid scale up of prevention of mother to child transmission of HIV and improvement in the coverage of other essential child health interventions including immunisations and increased access to water and sanitation. However, this has not been sufficient to reach the country's millennium development goals of reducing infant and under-5 mortality rates by two-thirds in 2015 .

As the country looks to a new set of sustainable development goals beyond 2015, there is a need to focus on essential interventions that have been shown to be effective in improving child health. Recent analyses in South Africa identified a set of priority interventions that can have an impact on stillbirths, ${ }^{4}$ maternal, newborn and child mortality. ${ }^{5}$ Interventions such as family planning can avert more than 7000 newborn and child lives, at a cost of US\$7 per year per user of family planning. ${ }^{6}$ Investing an additional US\$9 to US\$18 per capita in 13 
interventions to prevent diarrhoea can save more than 3000 additional child lives every year. ${ }^{7}$ Scaling up these essential maternal and child health interventions will require concerted effort and a strengthening of the health system, a process which has already been initiated by the government.

In 2011, South Africa initiated its primary healthcare (PHC) re-engineering programme in a bid to improve health systems performance and access to health. PHC re-engineering is aimed at positioning PHC as the mainstay of the health sector in responding to the quadruple burden of disease (HIV/tuberculosis (TB), maternal and child health, non-communicable burden of disease and violence and injury). South Africa's approach to PHC re-engineering relies heavily on $\mathrm{PHC}$ outreach teams which include professional nurses, health promotion practitioners and community health workers (CHWs).

Global evidence has shown that CHWs can effectively deliver interventions in primary healthcare including nutrition, maternal and child health, malaria control, TB control, HIV/AIDS prevention and control, mental health and non-communicable disease. ${ }^{8-13}$ A Cochrane review of CHW interventions identified 107 randomised controlled trials which showed promising benefits, compared with usual facility care in increasing immunisation uptake in children, improving breastfeeding rates until 6 months, reducing neonatal mortality and improving pulmonary TB care rates. ${ }^{14}$ The review also reported that CHWs interventions reduce child morbidity and mortality, maternal mortality and increase the likelihood of caregivers seeking care for children who are ill.

There is a small but growing evidence base of cost effectiveness studies of CHW interventions in low and middle-income countries. ${ }^{15} 16$ More recently, there is evidence of the cost-effectiveness of CHW interventions in reducing malaria and asthma,${ }^{17}$ mortality of neonates and children, ${ }^{17}$ malnutrition ${ }^{17}$ and increasing exclusive breastfeeding ${ }^{18} 19$ and increasing uptake of home-based HIV testing. ${ }^{20}$ However, there is still a need to provide more information on the cost and impact of community health worker interventions to aid priority setting and decision-making for the improvement of child health.

In this paper, we use the Lives Saved Tool (LiST), a widely used priority setting tool, to estimate the costs of scaling up interventions that can be delivered by CHWs at community level. ${ }^{21}$ LiST has been previously used in South Africa to identify the essential interventions that can save the lives of children, together with the costs of these interventions. ${ }^{5-7} 22$ It has also been used in other low and middle-income countries to assess the cost-effectiveness of community health worker programmes. ${ }^{15}$ Our paper describes the methods used in LiST to estimate the cost of deploying CHWs and the overall impact that the selected interventions can have on reducing child mortality. This information is necessary for South Africa, as it pursues the goal of Universal Health Care.

\section{METHODS}

This analysis used the LiST, a module in the Spectrum software, which models the impact of increased coverage of health interventions on maternal, newborn and child mortality. ${ }^{21}$ Within the Spectrum software, LiST interacts with other modules, the AIDS Impact Module, Family Planning Module and Demography Projections Module (DemProj) to model the impact of more than 60 interventions that affect cause-specific mortality. ${ }^{23}$ LiST is a deterministic mathematical model that compares the effect of various interventions on population level risk factors, as well as stillbirths and maternal, newborn and child deaths. ${ }^{21}{ }^{24}$ The primary model inputs are coverage of interventions and the outputs are changes in risk factors (such as stunting rates) and cause-specific mortality. Interventions included in the model can have an impact on single or multiple causes of death and risk factors, with outcomes changing based on the level of intervention coverage. Increasing the level of coverage of one or more interventions can thus lead to a reduction in associated risk factors or cause-specific mortality.

Intervention impact on mortality can be direct or indirect (through the reduction of risk factors). The direct impact of each of these interventions is modelled by multiplying its effectiveness estimate with the level of coverage, assuming all other interventions are kept constant. For example, an intervention with an effect estimate of 30\% can avert $30 \%$ of the associated cause-specific deaths if coverage for that intervention is $100 \%$.

The modelling methods used in LiST have been used in several studies. ${ }^{2526}$ In South Africa, LiST has been used to identify the potential cost and impact of scaling up interventions on stillbirths, ${ }^{4}$ diarrhoea ${ }^{27}$ and maternal, newborn and child mortality. ${ }^{28}{ }^{29}$ In our model, we use LiST to model the impact of interventions to reduce child mortality and then estimate the resources required for the portion of interventions that are delivered at community level. ${ }^{30}$

Nine interventions (described in table 1) available in LiST that can be delivered at community level and have been shown to effectively impact child mortality are used in the model. The focus on these interventions was because they can be delivered by CHWs at community level. The baseline coverage of all interventions included in LiST was maintained, and only scaled up for the nine community interventions, from baseline levels (2015) to full coverage at $99 \%$ (2030). Increases in coverage were assumed to be gradual and interpolated over the 15-year period.

The baseline mortality rates used were 41 deaths per 1000 live births for under-5 children and 13/1000 for neonates. ${ }^{31}$ The causes of newborn and child mortality ${ }^{32}$ are given in figure 1 . The relationship between the nine interventions scaled up in the model and the causes of death are shown in table 1 . The interventions are mainly focused on diarrhoea.

Table 2 shows the per cent delivery of each intervention at different levels in the base and target years. Taking promotion of breast feeding for example, the table shows that in the base year, the coverage of this intervention is 
Table 1 Description of interventions

\begin{tabular}{|c|c|c|c|}
\hline Intervention & Description of the intervention & affected & estimate \\
\hline $\begin{array}{l}\text { 1. Breastfeeding } \\
\text { promotion }\end{array}$ & $\begin{array}{l}\text { Breastfeeding promotion can be either one on-one or group meetings. It is } \\
\text { assumed that children } 1-5 \text { months of age who are exclusively breast fed do } \\
\text { not need breastfeeding promotion. }\end{array}$ & & \\
\hline $\begin{array}{l}\text { 2. Complementary } \\
\text { feeding }\end{array}$ & $\begin{array}{l}\text { This intervention only benefits children } 6-24 \text { months of age who are } \\
\text { living on more than a dollar a day. This can be delivered in the home, } \\
\text { community or clinic, by health professionals or health volunteers. It } \\
\text { includes the assumption that breast feeding should be continued for } \\
\text { children } 6-24 \text { months of age, (but does not affect breastfeeding rates). The } \\
\text { intervention includes education on the proper foods to prepare as well as } \\
\text { appropriate hygiene for food preparation. }\end{array}$ & & \\
\hline $\begin{array}{l}\text { 3. Vitamin A } \\
\text { supplementation }\end{array}$ & $\begin{array}{l}\text { This intervention covers the percent of children } 6-59 \text { months receiving full } \\
\text { coverage with Vitamin A. Full coverage of Vitamin A supplementation is } \\
\text { considered to be two doses of Vitamin A in the past year. It is assumed that } \\
\text { all children in a country with Vitamin A deficiency are in need of Vitamin A } \\
\text { for prevention. }\end{array}$ & Diarrhoea & $47 \%$ \\
\hline $\begin{array}{l}\text { 5. Hygienic } \\
\text { disposal of } \\
\text { children's stools }\end{array}$ & $\begin{array}{l}\text { Per cent of children's stools that are disposed of safely and contained. } \\
\text { Stools are considered to be contained if: (1) the child always uses a toilet/ } \\
\text { latrine, (2) the faeces are thrown in the toilet or latrine or (3) the faeces are } \\
\text { buried in the yard. }\end{array}$ & Diarrhoea & $20 \%$ \\
\hline $\begin{array}{l}\text { 6. Oral rehydration } \\
\text { solution (ORS) }\end{array}$ & $\begin{array}{l}\text { Per cent of children with diarrhoea given ORS from sachets. This includes } \\
\text { sachets or premixed solutions of ORS. }\end{array}$ & Diarrhoea & $93 \%$ \\
\hline $\begin{array}{l}\text { 7. Oral antibiotics } \\
\text { for the treatment } \\
\text { of pneumonia }\end{array}$ & $\begin{array}{l}\text { Proportion of children } 1-59 \text { months with suspected pneumonia or acute } \\
\text { respiratory infections (ARI)treated with antibiotics }\end{array}$ & Pneumonia & $70 \%$ \\
\hline
\end{tabular}

$25 \%$ and will be scaled up to $99 \%$ in the target year 2030 . In the base year, breastfeeding promotion is delivered $50 \%$ at community level and $25 \%$ each at outreach and clinic levels. While we assumed that overall intervention coverage for the nine interventions increased, the level assigned to each delivery channel remained the same. Setting the per cent delivery is essential to determining the resource requirements at the different levels. It is also important to note that LiST models the overall impact of each intervention, and intervention impact does not take into consideration the model of delivery (whether delivered at community or facility level).

\section{Estimation of costs and resource requirements}

Costs were modelled from a provider perspective, using the costing module in LiST. The module uses an ingredients approach to costing, based on four components: personnel and labour; drugs and supplies; other recurrent costs and capital costs. In the analysis for costs of community health workers, the items included are personnel and labour and drugs and supplies. Staff remuneration is based on current salary structures of health workers in South Africa, with an allowance made for annual cost of living adjustments at $5.6 \%$ per annum. ${ }^{33}$ The unit costs of drugs and supplies are based on international drug prices from Unicef and the Management for Sciences Health International Drug Price Indicator. ${ }^{34} 35$

The primary personnel input in LiST are staff time, which is then converted to annual staff costs. Thus, LiST cannot for example calculate the number of personnel required for a particular intervention but can be used to 


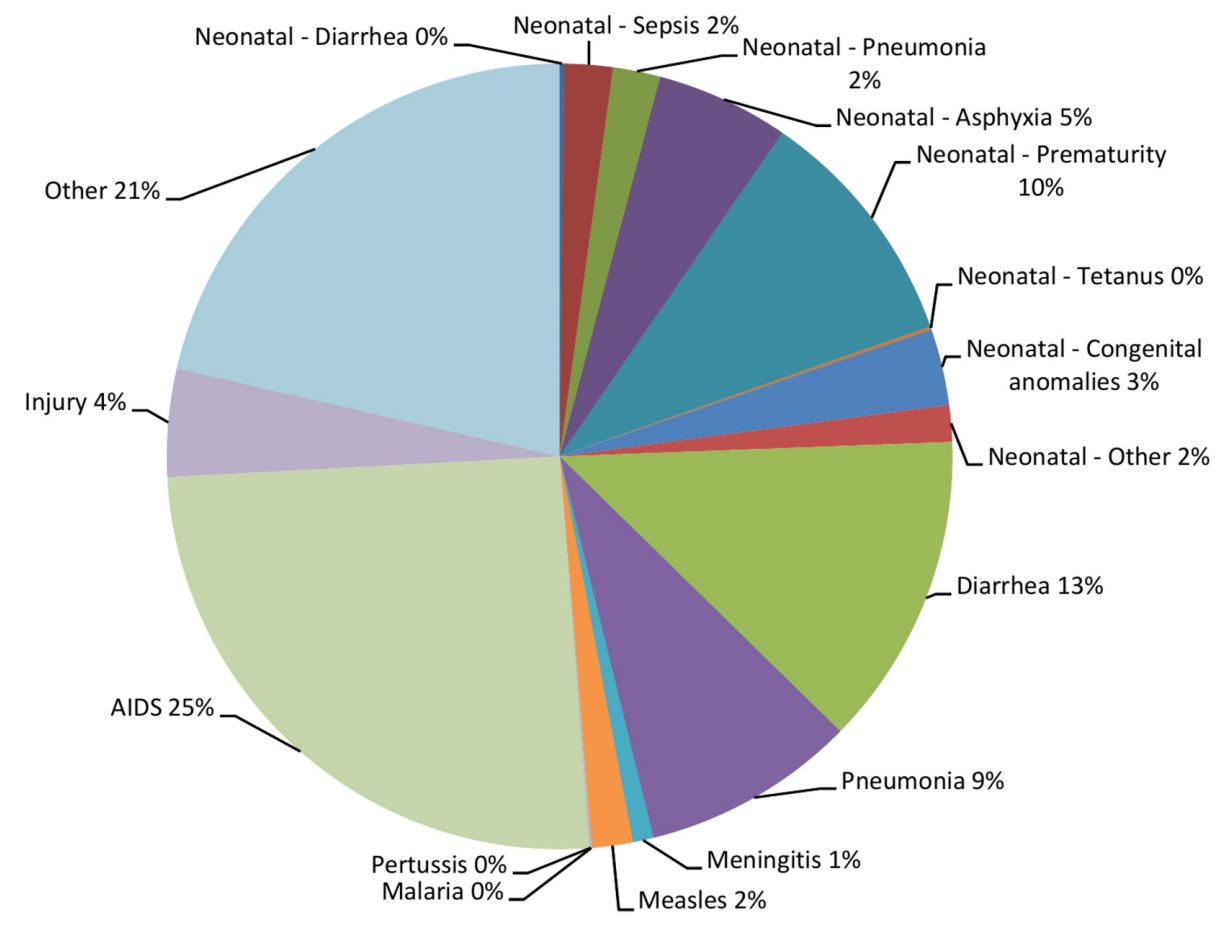

Figure 1 Causes of death in children under 5 years used in LiST (adapted from MRC, 2010). LiST, Lives Saved Tool.

estimate the effort required to scale up an intervention (in terms of staff time).

Costs were estimated in South African Rand (ZAR) and converted to US $\$$, at an average exchange rate of US\$1 to ZAR13 in 2015. All costs were adjusted to 2015 using the Consumer Price Index.

\section{RESULTS}

The model estimates a total fertility rate of 2.4 , approximately 1.4 million pregnancies and 1.2 million births in 2015. The projected number of pregnancies and births in 2030 reduces to 1.2 million and 1 million, respectively.

Table 2 Per cent intervention coverage and delivery at different levels

\begin{tabular}{|c|c|c|c|c|c|c|c|c|}
\hline \multirow[b]{3}{*}{ Interventions } & \multicolumn{2}{|l|}{ Coverage } & \multicolumn{6}{|c|}{ Delivery channels } \\
\hline & \multirow[b]{2}{*}{$\begin{array}{l}\text { Baseline } \\
\text { year }\end{array}$} & \multirow[b]{2}{*}{$\begin{array}{l}\text { Target } \\
\text { year }\end{array}$} & \multicolumn{2}{|c|}{ Community } & \multicolumn{2}{|l|}{ Outreach } & \multicolumn{2}{|l|}{ Clinic } \\
\hline & & & $\begin{array}{l}\text { Baseline } \\
\text { year }\end{array}$ & $\begin{array}{l}\text { Target } \\
\text { year }\end{array}$ & $\begin{array}{l}\text { Baseline } \\
\text { year }\end{array}$ & $\begin{array}{l}\text { Target } \\
\text { year }\end{array}$ & $\begin{array}{l}\text { Baseline } \\
\text { year }\end{array}$ & $\begin{array}{l}\text { Target } \\
\text { year }\end{array}$ \\
\hline Promotion of breast feeding & 25 & 99 & 50 & 50 & 25 & 25 & 25 & 25 \\
\hline $\begin{array}{l}\text { Complementary feeding-education } \\
\text { only }\end{array}$ & 10 & 99 & 50 & 50 & 0 & 0 & 50 & 50 \\
\hline Vitamin A supplementation & 50 & 99 & 50 & 50 & 50 & 50 & 0 & 0 \\
\hline Hand washing with soap & 17 & 99 & 100 & 100 & 0 & 0 & 0 & 0 \\
\hline Hygienic disposal of children's stools & 40.5 & 99 & 100 & 100 & 0 & 0 & 0 & 0 \\
\hline Oral rehydration solution & 50 & 99 & 50 & 50 & 0 & 0 & 50 & 50 \\
\hline $\begin{array}{l}\text { Oral antibiotics: case management } \\
\text { of pneumonia in children }\end{array}$ & 73.2 & 99 & 50 & 50 & 0 & 0 & 50 & 50 \\
\hline $\begin{array}{l}\text { Therapeutic feeding-for severe } \\
\text { wasting }\end{array}$ & 45 & 99 & 20 & 20 & 0 & 0 & 80 & 80 \\
\hline $\begin{array}{l}\text { Treatment for moderate acute } \\
\text { malnutrition }\end{array}$ & 10 & 99 & 20 & 20 & 0 & 0 & 80 & 80 \\
\hline
\end{tabular}


Table 3 Total number of deaths (all interventions)

\begin{tabular}{lcc}
\hline Age group & Baseline & Scale up to 99\% \\
\hline & 2015 & 2030 \\
\hline$<1$ month & 13356 & 12435 \\
1-59 months & 26857 & 17569 \\
\hline Total (0-59 months) & 40214 & 30004 \\
\hline
\end{tabular}

\section{Overall intervention impact on child mortality}

Table 3 provides the estimated number of deaths at baseline in 2015 and after full scale in 2030. The number of deaths reduces from approximately 40214 in 2015 to 30004 in 2030. Thus, 10210 deaths are prevented in this period, out of which a total of 8322 deaths prevented are attributed to the nine community interventions that were scaled up in this analysis (table 4). Hand washing with soap (22\%) accounts for the highest number of deaths prevented, followed by therapeutic feeding (21\%) and oral rehydrating solution (ORS; $17 \%)$. The top five interventions account for $82 \%$ of all deaths prevented.

\section{Estimations of resource requirements}

The total costs of all the interventions used in the analysis (including costs of all delivery channels, ie, community, outreach and health facility) are estimated to be US $\$ 74$ million (US\$1 per capita) in 2015 (table 5). This is expected to rise to US $\$ 565$ million (US $\$ 10$ per capita) if interventions are scaled up to $99 \%$ coverage in 2030 . In comparison, the costs of the community component are US\$19.8 million (US\$0.37 per capita) in 2015 and US $\$ 169.5$ million in 2030. The difference in the total and community costs shows the impact that a higher cadre of staff would have in relation to costs. The required number of workers was calculated by converting the personnel time estimated in LiST.

Table 4 Additional deaths prevented by nine community interventions, 2030

\begin{tabular}{lcc}
\hline Intervention & Number of deaths prevented & $\%$ deaths prevented \\
\hline Hand washing with soap & 1828 & $22 \%$ \\
Therapeutic feeding -for severe wasting & 1730 & $21 \%$ \\
Oral rehydration solution & 1426 & $17 \%$ \\
Oral antibiotics: case management of pneumonia in children & 1025 & $12 \%$ \\
Appropriate complementary feeding & 822 & $10 \%$ \\
\hline Hygienic disposal of children's stools & 543 & $7 \%$ \\
Vitamin A supplementation & 394 & $5 \%$ \\
Promotion of breast feeding & 319 & $4 \%$ \\
\hline Treatment for moderate acute malnutrition & 235 & $3 \%$ \\
\hline Total & 8322 & $100 \%$ \\
\hline
\end{tabular}

This table provides the additional number of deaths prevented attributable to the nine community interventions scaled up to full coverage.

Table 5 Costs and resource requirements (US\$)

\begin{tabular}{|c|c|c|c|c|}
\hline \multirow[b]{2}{*}{ Interventions } & \multicolumn{2}{|c|}{2015} & \multicolumn{2}{|c|}{2030} \\
\hline & Total & Community & Total & Community \\
\hline Promotion of breast feeding & 1123509 & 561754 & 10038173 & 5019086 \\
\hline Complementary feeding (education only) & 1149336 & 122720 & 25679246 & 2741903 \\
\hline Vitamin A supplementation & 549421 & 71866 & 2394368 & 280552 \\
\hline Hand washing with soap & 2375468 & 2375468 & 37526223 & 37526223 \\
\hline Hygienic disposal of children's stools & 5659204 & 5659204 & 37526223 & 37526223 \\
\hline Oral rehydration solution & 19270311 & 2575185 & 34500213 & 4086458 \\
\hline $\begin{array}{l}\text { Oral antibiotics: case management of } \\
\text { pneumonia in children }\end{array}$ & 3298578 & 378909 & 10045584 & 1106962 \\
\hline Therapeutic feeding - for severe wasting & 28213620 & 5621596 & 135840638 & 27062171 \\
\hline Treatment for moderate acute malnutrition & 12549660 & 2500542 & 271778014 & 54143689 \\
\hline Total & 74189107 & 19867246 & 565328681 & 169493266 \\
\hline \multicolumn{5}{|l|}{ Personnel time (hours) } \\
\hline Community health workers & & 3339796 & & 11140869 \\
\hline
\end{tabular}

Total costs include costs of all delivery channels (community, outreach and health facility). 
Considering only the baseline costs at community level, hygienic disposal of stools is estimated to have the highest cost of labour at US $\$ 5.7$ million. Therapeutic feeding for wasting comes in second at US\$5.6 million and oral rehydration solution has the third highest cost of US\$2.6 million. When interventions are at scale in 2030, the highest costs are projected for treatment of moderate acute malnutrition (US\$54 million), hand washing with soap and disposal of stools (US\$37million each) and therapeutic feeding for wasting (US\$37 million).

Approximately 3.3 million hours of work per year at the community level are required at baseline, compared with 11.1 million hours when interventions are fully scaled up. Based on a full-time equivalent working a 6-hour day for a full year, we the required community health workforce to deliver the interventions used in this model will be about 3000 at baseline and 11000 at full coverage.

\section{DISCUSSION}

This analysis used the LiST, a widely used priority setting tool to estimate the cost and impact of interventions delivered at community level to prevent child mortality. The results show that scaling up nine interventions that are conducted at both community and facility level can prevent an additional 8300 lives per year. The top five interventions: hand washing with soap, therapeutic feeding for wasting, ORS, oral antibiotics for pneumonia and appropriate complementary feeding, account for $82 \%$ of all additional deaths prevented, that is, implementing only these five interventions at scale can prevent an additional 6800 child deaths per year.

This is an important finding as it has implications for considerations when choosing the most effective interventions to meet the new sustainable development goals for child health. Considering that not all interventions can be fully implemented given budgetary constraints, focusing on the identified five most effective interventions can contribute to achieving the desired results. Other considerations such as cost implications have to be made when choosing which interventions to implement.

In 2011, it was estimated that there were more than 72000 community health workers in South Africa, delivering various interventions. ${ }^{36}$ In our projection, we estimated that approximately 11000 community health workers would be required to deliver the nine interventions used in this analysis at scale. This could be an underestimate, and we have no basis for comparisons with other studies. Caution should be taken when considering our estimate, because it is based on a projected baseline level of coverage for the modelled interventions, level of effort required to deliver the interventions and an annual salary, all of which could be different in other models.

The labour costs of community health workers have been provided in this analysis. We show that at scale, an estimated cost of US $\$ 169.5$ million (US\$3 per capita) per year will be required. The top five most effective interventions are also the most costly, probably because they are more personnel intense, with a lot of time spent on extensive demonstrations. Provision of oral antibiotics for example requires diagnosis, treatment and follow-up. It is important to note though, that the overall cost of an intervention will be influenced by among other things, the level of coverage, with more effort required to scale up low coverage interventions.

The costs provided in this analysis are likely an underestimate of the true costs of deploying community health workers, which have been shown to be substantial. Equipment costs have not been included nor have the usually large administrative costs also been considered. Future research should look into providing the overall cost structure as this has important implications for how health workers are deployed and accounted for. Future analyses should take these costs into consideration, as it has been shown that they can contribute to the overall cost-effectiveness of interventions. ${ }^{3738}$

This analysis also had a limitation in that it did not consider the interventions included as part of a package of interventions that can be delivered by a single health worker. The interventions are standalone. While looking at the individual impact of interventions is useful and can help to understand the value of each intervention, this does not truly reflect the way most interventions are implemented in reality, as packages. It is therefore possible that we potentially overestimated the overall health impact of the interventions included in this analysis. Further, we also could have overestimated the costs, since savings tend to be higher when interventions are packaged than when they standalone. However, other considerations should also be made on how packaged community health services would work and on whether a single health worker loaded with several different messages to deliver to a home will be as effective as one who is focused on one specific message, for example, breastfeeding promotion.

The interventions included in this analysis have been shown to be effective in reducing child mortality. Extensive reviews of the literature were undertaken to gather information on intervention effectiveness by the Child Health Epidemiology Reference Group. ${ }^{39}$ In this analysis, we have shown the potential impact that these interventions can have on reducing child mortality in South Africa. However, cognisance should be taken of the challenges that could be faced with deploying CHWs in the South African context. Healthcare in South Africa remains mainly facility based, and provided by professional health workers, while CHWs mainly facilitate health promotion. Therefore, an intervention such as case management of pneumonia, which requires some level of diagnostic ability as implemented in other settings, ${ }^{40}{ }^{41}$ might not work for CHWs in South Africa. A lot of effort will have to be placed in training CHWs and redefining their roles. Such efforts would incur costs that have not been considered in this study. The usefulness of our study is that it puts forward evidence that can be used to argue for the expansion of the roles of South African CHWs. 
We focused on only nine interventions that can be delivered at community level, by maintaining constant coverage of other child health interventions. This may not be very realistic since in the real world, coverage of the other interventions is likely to increase, resulting in a lower burden of under-5 mortality by 2030 . It is therefore possible that we have overestimated the total number of deaths prevented.

Furthermore, the LiST model assumes that the health system interventions are delivered at uniformly high quality. This is unlikely given drug shortages, healthcare worker attitudes and institutional challenges. Significantly more resources are probably required to address such issues.

\section{CONCLUSION}

South Africa has made significant progress with regard to reducing child mortality although this was not sufficient to meet the MDG deadline in 2015. As the new sustainable development goals materialise, and South Africa heads towards Universal Health Care, understanding what the best package is and how it can be delivered is essential. To do this, there is a need to consider essential and effective interventions that will have the most impact on saving the lives of South African children. In this paper, we have provided information on the cost and impact of nine effective interventions that can be delivered at community level. We show that implementing just five of these interventions can prevent as many as 6800 additional deaths of children every year. The community health worker costs of implementing the nine interventions do not seem to be substantial, at R41 per capita. This seems to be well within the scope and affordability of the South African health budget.

Contributors LN and KH conceived the study and participated in the design. LN and $\mathrm{LC}$ conducted the analysis of the data. All authors participated in interpretation of data, drafting and critical revision of the manuscript and approved the final version.

Funding The researchers time was funded through PEECHi-A Division of Wits Health Consortium (Pty) Ltd.

Competing interests None declared.

Provenance and peer review Not commissioned; externally peer reviewed.

Data sharing statement The model data can be made available to interested researchers. No additional data available.

Open Access This is an Open Access article distributed in accordance with the Creative Commons Attribution Non Commercial (CC BY-NC 4.0) license, which permits others to distribute, remix, adapt, build upon this work non-commercially, and license their derivative works on different terms, provided the original work is properly cited and the use is non-commercial. See: http://creativecommons.org/ licenses/by-nc/4.0/

(C) Article author(s) (or their employer(s) unless otherwise stated in the text of the article) 2017. All rights reserved. No commercial use is permitted unless otherwise expressly granted.

\section{REFERENCES}

1. Liu L, Johnson HL, Cousens S, et al. Global, regional, and national causes of child mortality: an updated systematic analysis for 2010 with time trends since 2000. Lancet 2012;379:2151-61.
2. Stats SAStatistics South Africa. Levels and trends of morbidity and mortality among children aged under-five years in South Africa, 2006-2010: Pretoria, South Africa, 2012.

3. Dorrington RE, Bradshaw D L. Rapid mortality surveillance report 2014. Cape Town, South Africa: South African Medical Research, 2015.

4. Michalow J, Chola L, McGee S, et al. Triple return on investment: the cost and impact of 13 interventions that could prevent stillbirths and save the lives of mothers and babies in South Africa. BMC Pregnancy Childbirth 2015;15:39.

5. Chola L, Pillay Y, Barron P, et al. Cost and impact of scaling up interventions to save lives of mothers and children: taking South Africa closer to MDGs 4 and 5. Glob Health Action 2015;8:27265.

6. Chola L, McGee S, Tugendhaft A, et al. Scaling up family planning to reduce maternal and child mortality: the potential costs and benefits of modern contraceptive use in South Africa. PLoS One 2015;10:e0130077.

7. Chola L, Michalow J, Tugendhaft A, et al. Reducing diarrhoea deaths in South Africa: costs and effects of scaling up essential interventions to prevent and treat diarrhoea in under-five children. BMC Public Health 2015;15:394.

8. Gilson L, Walt G, Heggenhougen K, et al. National community health worker programs: how can they be strengthened? J Public Health Policy 1989;10:518-32.

9. Ofosu-Amaah V. National experience in the use of community health workers: a review of current issues and problems. Geneva: World Health Organization, 1983

10. Bhattacharyya K, Winch P, LeBan K, et al. Community health worker incentives and disincentives: how they affect motivation, retention, and sustainability. Virgian Basics II, 2001.

11. Lehmann U, Sanders D. Community health workers: what do we know about them? the state of the evidence on programmes, activities, costs and impact on health outcomes of using community health workers. Geneva: Evidence and Information for Policy, Department of Human Resource for Health World Health Organisation, 2007.

12. Bhutta ZA, Lassi ZS, Pariyo G, et al. Global experience of community health workers for delivery of health related millennium development goals: systematic review, country case studies and recommendations for scaling up: Global Health Workforce Alliance: Health workers for all and all for health workers, 2010.

13. Lewin S, Munabi-Babigumira S, Glenton C, et al; Lay health workers in primary and community health care for maternal and child health and the management of infectious diseases (Review): The Cochrane Library, 2010.

14. Lewin S, Munabi-Babigumira S, Glenton C, et al. Lay health workers in primary and community health care for maternal and child health and the management of infectious diseases. Cochrane database of Systematic Reviews Update in progress.

15. McPake BEI, Witter S, Kielmann K, et al; Cost-effectiveness of community-based practitioner programmes in Ethiopia, Indonesia and Kenya Bull World Health Organ. , 2015:93, 631-9.

16. Perry HB, Zulliger R, Rogers MM et al. Community health workers in low-, middle-, and high-income countries: an overview of their history, recent evolution, and current effectiveness. Annu Rev Public Health 2014;35:399-421.

17. Henry Perry S. HOW EFFECTIVE ARE COMMUNITY HEALTH WORKERS? An overview of current evidence with recommendations for Strengthening Community Health Worker Programs to accelerate Progress in achieving the Health-related Millennium Development Goals, 2012.

18. Chola L, Nkonki L, Kankasa C, et al. Cost of individual peer counselling for the promotion of exclusive breastfeeding in Uganda. Cost Eff Resour Alloc 2011;9:11.

19. Desmond C, Bland RM, Boyce G, et al. Scaling-up exclusive breastfeeding support programmes: the example of KwaZulu-Natal. PLoS One 2008;3:e2454.

20. Tabana H, Nkonki L, Hongoro C, et al. A Cost-Effectiveness analysis of a Home-Based HIV counselling and testing intervention versus the Standard (Facility based) HIV testing Strategy in Rural South Africa. PLoS One 2015;10:e0135048.

21. Walker N, Tam Y, Friberg IK. Overview of the Lives Saved Tool (LiST). BMC Public Health 2013;13 Suppl 3(Suppl 3):S1.

22. Chopra M, Daviaud E, Pattinson R, et al. Saving the lives of South Africa's mothers, babies, and children: can the health system deliver? Lancet 2009;374:835-46.

23. Stover J, McKinnon R, Winfrey B. Spectrum: a model platform for linking maternal and child survival interventions with AIDS, family planning and demographic projections. Int J Epidemiol 2010;39 Suppl 1(Suppl 1):i7-i10. 
24. Johns Hopkins Bloomberg School of Public Health.. LiST: The Lives Saved Tool. An evidence-based tool for estimating intervention impact. Secondary LiST: The Lives Saved Tool. An evidence-based tool for estimating intervention impact 2010. http://www.jhsph.edu/ dept/ih/IIP/list/index.html.

25. Boschi-Pinto C, Black RE. Development and use of the Lives Saved Tool: a model to estimate the impact of scaling up proven interventions on maternal, neonatal and child mortality. Int $J$ Epidemiol 2011;40:520-1.

26. Fischer Walker CL, Walker N. The Lives Saved Tool (LiST) as a model for diarrhea mortality reduction. BMC Med 2014;12:70.

27. Chola L, Michalow J, Tugendhaft A, et al. Reducing diarrhoea deaths in South Africa: costs and effects of scaling up essential interventions to prevent and treat diarrhoea in under-five children. BMC Public Health 2015;15:394.

28. Chola L, Pillay Y, Barron P, et al. Cost and impact of scaling up interventions to save lives of mothers and children: taking South Africa closer to MDGs 4 and 5. Glob Health Action 2015;8:27265.

29. Chopra M, Daviaud E, Pattinson R, et al. Saving the lives of South Africa's mothers, babies, and children: can the health system deliver? Lancet 2009;374:835-46.

30. Friberg IK, Walker N. Using the Lives Saved Tool as part of evaluations of community case management programs. J Glob Health 2014;4:020412.

31. Dorrington RE, Bradshaw D, Laubscher R, et al. Rapid mortality surveillance report 2012. Cape Town, South Africa: : South African Medical Research Council, 2014.
32. Wyk VP-van, Msemburi W, Laubscher R, et al. Second National Burden of Disease Study South Africa: national and subnational mortality trends, 1997-2009. The Lancet 2013;381:S113.

33. DPSA. Remuneration policy documents. secondary remuneration policy documents. $2015 \mathrm{http} / / / w w w . d p s a . g o v . z a / d p s a 2 g / r_{-}$ documents.asp.

34. UNICEF. UNICEF Supply Catalogue. Secondary UNICEF Supply Catalogue. 2014 www.supply.unicef.org.

35. Frye JE. International drug price indicator guide, 2012.

36. NDOH. CHW Audit Report Draft 1. Pretoria, South Africa: : NDOH, 2011.

37. Nkonki LL, Daviaud E, Jackson D, et al. Costs of promoting exclusive breastfeeding at community level in three sites in South Africa. PLoS One 2014;9:e79784.

38. Chola L, Nkonki L, Kankasa C, et al. Cost of individual peer counselling for the promotion of exclusive breastfeeding in Uganda. Cost Eff Resour Alloc 2011;9:11.

39. Boschi-Pinto C, Young M, Black RE, et al. The Child Health Epidemiology Reference Group reviews of the effectiveness of interventions to reduce maternal, neonatal and child mortality. Int $J$ Epidemiol 2010;39 Suppl 1(Suppl 1):i3-i6.

40. Rutebemberwa E, Kadobera D, Katureebe S, et al. Use of community health workers for management of malaria and pneumonia in urban and rural areas in eastern Uganda. Am J Trop Med Hyg 2012;87(5 Suppl):30-5.

41. Graham K, Sinyangwe C, Nicholas S, et al. Rational use of antibiotics by community health workers and caregivers for children with suspected pneumonia in Zambia: a cross-sectional mixed methods study. BMC Public Health 2016;16:897. 